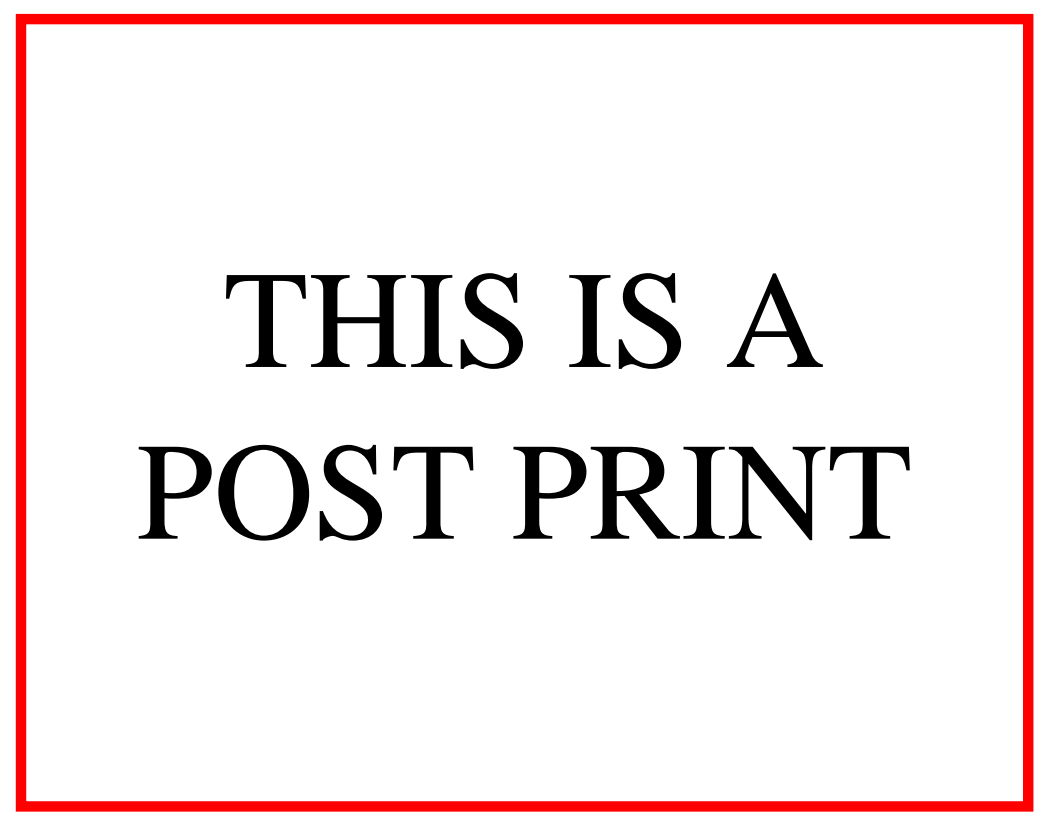




\title{
An Exploration of the Panther Mountain Crater Impact Using Spatial Data and GIS Spatial Correlation Analysis Techniques
}

\author{
Sawyer Reid Stippa ${ }^{1}$, Konstantinos P. Ferentinos ${ }^{2}$, and George P. Petropoulos ${ }^{1,3,4}$
}

\begin{abstract}
Identification and mapping of hypervelocity impact crater (HICs) sites require significant effort on ground truthing data collection and local instrument-driven research. The recent advancements in Earth observation (EO) technology and geographical information systems (GIS) have increased our ability to study HICs. With EO imagery and relevant spatial data now readily available online at no cost, GIS and remote sensing provide a very attractive option in investigating the Earth's surface. In this framework, our study addresses the use of GIS and EO techniques by looking at a possible impact crater in upstate New York, United States. The Panther Mountain crater is thought to have been created by a meteor impact over 300,000 years ago during the Devonian or Mississippian geologic periods. Using freely available data from previous research, this study aimed at mapping land cover and geologic data and analyzing their correlation at Panther Mountain and it surrounding area. Findings of the study have showed encouraging results. A correlation between Panther Mountain's bedrock geology and vegetation was reported to be higher than the coefficient of the surrounding area. Similarly, the correlation between Panther Mountain's surficial geology type and vegetation was significantly lower than that of the other region. The significant difference in correlations between the two regions supports the Panther Mountain impact site. All in all, the present study also produced encouraging results as regards to the use of GIS in identifying potential hypervelocity crater sites.
\end{abstract}

\subsection{INTRODUCTION}

The use of geographic information systems (GIS) to study the Earth's surface has had significant impact on our knowledge of the planet's past and current geomorphic history. In much the same way, our improvements

${ }^{1}$ Department of Geography and Earth Sciences, University of Aberystwyth, Wales, United Kingdom

${ }^{2}$ Department of Agricultural Engineering, Institute of Soil \& Water Resources, Hellenic Agricultural Organization "Demeter", Athens, Greece

${ }^{3}$ Department of Soil Water Resources, Institute of Industrial \& Forage Crops, Hellenic Agricultural Organization "Demeter", Larissa, Greece

${ }^{4}$ Department of Mineral Resources Engineering, Technical University of Crete, Crete, Greece upon GIS techniques have allowed for further study of our planetary neighbors, both locally and galactically. However, much information is yet to be discovered about our own planet. A surface as actively changing (geophysically, geochemically, etc.) as Earth's, makes studying it all the more challenging.

Much like studies done on the Martian surface to explain its surficial history, similar geospatial techniques can be applied to study the Earth's history. GIS and Earth observation (EO) play "a substantial role for the identification of possible terrestrial impact structures, for mapping target-rock lithologies and deciphering the structural style of known craters" (Zumsprekel \& Bischoff, 2005). Terrestrial impact craters are known to exist in many places on our planet's surface. Many of them have been located and studied using aerial and satellite imagery. The Earth Impact Database, run by the

Techniques for Disaster Risk Management and Mitigation, Geophysical Monograph 244.

First Edition. Edited by Prashant K. Srivastava, Sudhir Kumar Singh, U. C. Mohanty, and Tad Murty.

(c) 2019 American Geophysical Union. Published 2019 by John Wiley \& Sons, Inc. 
Planetary and Space Science Centre (PASSC), maintains records of known impact structures all over the world. It has been speculated that Panther Mountain crater in upstate New York is a buried terrestrial impact site, however, it has not yet been officially acknowledged as such by the PASSC. It does, however, belong to the list of suspected Earth impact sites (SEIS) as a possible terrestrial crater (Rajmon, 2007).

Panther Mountain is part of the greater Catskill Park and is currently maintained and protected by New York State's Forest Reserve. The rosette drainage pattern around the mountain is unlike the dendritic shape the rest of the range exhibits. Geologist George Chadwick believed this shape to be caused by rising gas under the surface (Guterl, 2000). In the 1940s the Dome Gas Company drilled $1.8 \mathrm{~km}$ into the mountain only to find minor amounts of natural gas. Not until the 1970s was greater effort put into studying the unknown source of the mountain's shape. The late Dr. Yngvar Isachsen, a geologist who was part of the New York Geological Survey, believed the circular structure was caused by a buried impact crater. He did several studies of the area where he examined the compact fracture pattern of the sedimentary rock. Isachsen was also able to show a gravitational pull at Panther Mountain different from the other surrounding peaks. However, he was unable to gain support for the discovery of iron spherules, which indicate a high possibility of meteor impact. In 1999, a group of Canadian specialists were able to confirm the existence of shock lamellae in tiny quartz crystals, which could only have resulted from a large impact (Guterl, 2000). Isachsen's research continued until his death in 2001. Unfortunately, there has been no further research done on Panther Mountain since.

The existing methods of identifying terrestrial impact craters rely on different criteria than those used in identifying craters on the Moon or Mars, where surface structures are more capable of withstanding changing environmental conditions. To determine the existence of terrestrial craters, the identification of microscopic and macroscopic features, such as shatter cones, is considered more evidential than simply viewing circular structures. This remains the case because of the complexity of the Earth's surface, where surficial features may be caused by other geomorphic processes.

The identification methods can be tedious, however, and often require funding and resources (such as drilling equipment and gravity measuring devices). With the onset of more affordable and detailed remote sensing imagery, the possibility of extracting information from potential terrestrial impact sites (and the Earth's surface as a whole) can become more accessible to the general public and lead to a greater understanding of our planet's geomorphic history.
Since the Panther Mountain crater site was first detected in the 1940s, there has been a minimal amount of scientific evidence suggesting its location as an impact site. To the authors' knowledge, no attempts have been made to study the area with available GIS data sets. Consequently, there is a lack of definitive remotely sensed data providing evidence for a meteorite impact. Significant amounts of research involved locating sources of detailed spatial information, such as surficial and bedrock mineralogy maps.

Land cover and geologic mapping have been a proven success in the GIS community. Numerous studies have used different GIS software packages in analyzing vegetation and mineralogy. More specifically, there have been many studies examining the relationship between soil type and vegetation. A high correlation was found to exist between forest types and soil types in a study published by Gerdol et al. (1985). Another study performed on a mixed-oak forest found correlations to exist between vegetation diversity and soil physicochemical properties and soil enzyme activities (Rodríguez-Loinaz et al., 2008). A study by Chen et al. (2007) in northwestern China found a positive correlation between soil organic matter and total vegetation cover. It was found that "biodiversity was closely related to soil nutrients" in $\mathrm{Mu} \mathrm{Su}$ Sandland, China (Yang et al., 2007) and in Huanjiang County, China, there was a positive correlation between soil bacteria and vegetation (He et al., 2008). Another study conducted in southwest China showed a correlation between soil texture and water content with vegetation (Xu et al., 2008).

There have also been many studies examining the relationship between bedrock and vegetation, either directly or through soil interaction. One study examined the relationship between vegetation diversity and soil as a result of the geologic history of the area (Pastor et al., 1982). Puy and Moat (1996) used GIS analysis to study correlation between vegetation and bedrock and found that "the primary vegetation is very strongly influenced by the type of rock on which it occurs." Willard et al. (2005), in a study concerning forest type in the Appalachian Mountains, found that "the occurrence of white ash, sugar maple and eastern hemlock were related significantly to bedrock geology type." Another report examined the relationship between sedimentary bedrock and with certain mineral deposits and found that "soil element concentration varied with bedrock chemistry" (Neff et al., 2006).

Several studies addressed bedrock-fissures that could have an impact on vegetation. Aich and Gross (2008) indicated that the bedrock-fracturing had a strong influence on vegetation growth, specifically where bedrock consists of the majority of the land cover and where the top soil layer is thin. A similar study also indicated 
that bedrock-fracturing provided positive linear growth for vegetation (Stothoff et al., 1999). A study done at the University of Massachusetts, Amherst, by Searcy et al. (2003) revealed significant differences in vegetation distribution with respect to bedrock.

Several of the previous studies described bedrock as having a significant relationship with surface vegetation. With complex-crater formation having a significant impact on underlying bedrock, it is possible that the bedrock beneath Panther Mountain affects vegetation differently than the bedrock of the surrounding area. It has also been shown in several of the studies that soil type and vegetation can be correlated. It can therefore be presumed that soil interaction with vegetation as a result of bedrock redistribution under Panther Mountain may provide evidence for an impact crater.

The purpose of this study is to provide additional evidence supporting the argument that Panther Mountain, New York, is the location of a terrestrial meteor impact crater, using GIS data. This is achieved by examining the differentiation of correlations between vegetation and geology at and around the mountain. It is necessary to determine a correlation between variables both inside and outside the crater location. Therefore, it is the goal of this study to differentiate spatial relationships between vegetation and geology. This is performed by (1) using spatial information on land cover to map vegetation types inside and outside the proposed crater site, (2) using geology classifications to map mineralogy and soil types inside and outside the proposed crater site, and (3) examining correlations between geology and vegetation for both inside and outside the proposed crater site.

\subsection{MATERIALS}

\subsubsection{Study Area}

Panther Mountain is located in the town of Shandaken, Ulster County, in upstate New York, USA. The exact location of the site is at latitude/longitude 42.056389, -74.395. Panther Mountain itself has a maximum elevation of $1,134 \mathrm{~m}$ (base elevation at $834 \mathrm{~m}$ above sea level) and the proposed crater site has a diameter of $10 \mathrm{~km}$ (Figure 10.1). The mountain is circumvented by Esopus and Woodland Creeks, which outline the unique rosette circular pattern of the site. The mountain is surrounded on all sides by high ridges, thereby contributing to the belief that the site is known to be a complex crater formation rather than just simple crater type (Isachsen et al., 1994; Isachsen, 1998; Donofrio, 2010).

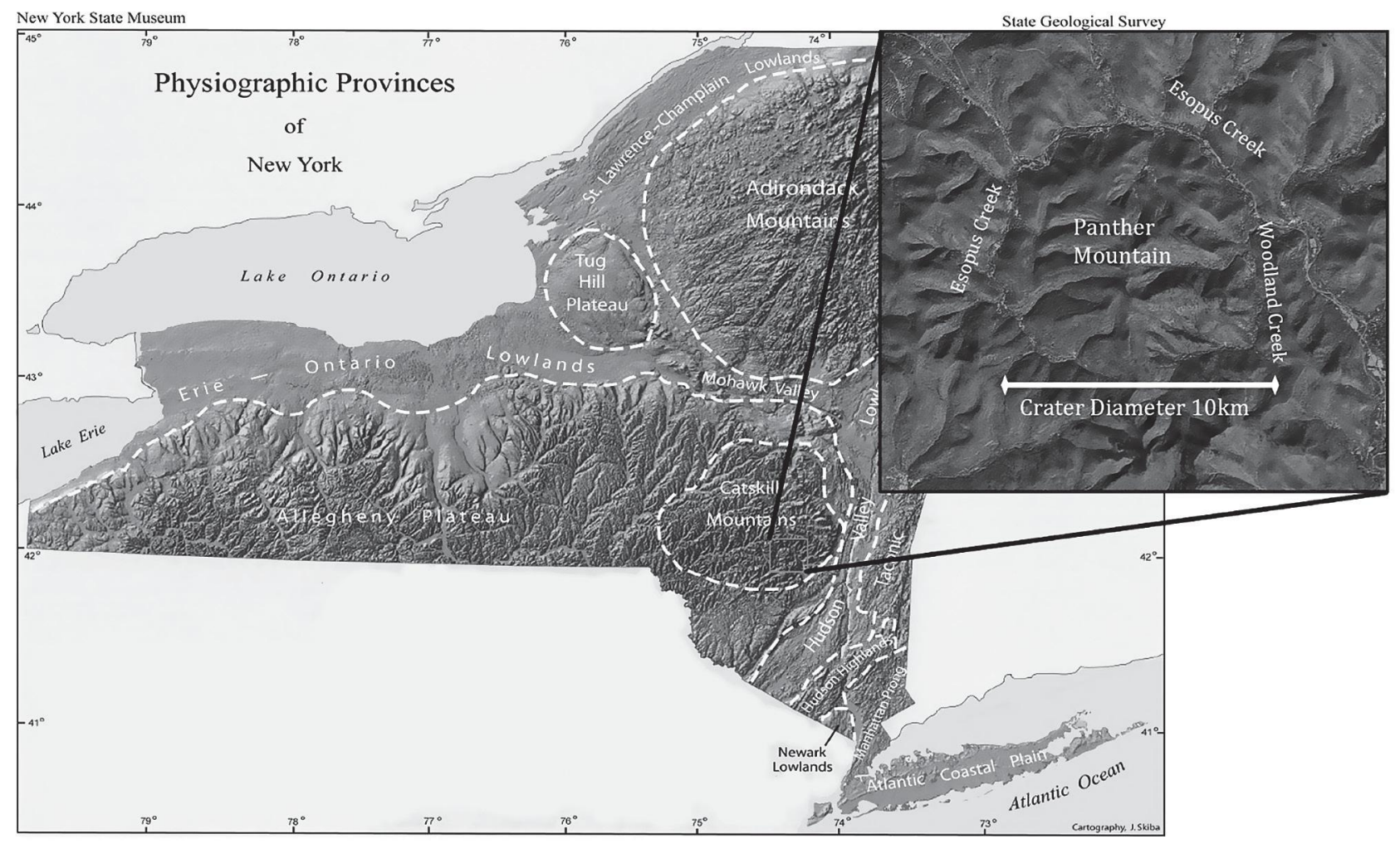

Figure 10.1 Location of the Catskill Mountains and the greater Allegheny Plateau in New York State. The study area of Panther Mountain is highlighted. 
The surrounding area (outside of the crater site) is home to the remaining Catskill peaks, which make up the extended region known as the Catskill Mountains. Areas bordering the crater site were used for classification comparisons. This primarily includes regions within the Catskill Mountains. The Catskill Mountains were formed over 300 million years ago during significant erosion and sedimentary redistribution of the Acadian Mountains to the east. It is during this time that some have predicted the meteor impact to have formed the current crater site. Extended periods of sedimentary distribution, erosion, and possible gravitational uplift led to the enlargement of Panther Mountain and the subsequent complex crater we see today. Based on the review of well cuttings, the estimated percentages of rock types that make up the impact site consist of $50 \%$ sub greywacke, $40 \%$ red silty shale, and $10 \%$ pebbly conglomerate (Isachsen et al., 1994).

Much of the land cover at Panther Mountain is protected forest reserve, consisting of the typical Catskill Mountain vegetation. This includes the traditional hardwood forest of birch, beech, and maple and boreal forests of red spruce and balsam fur in the higher elevations (Isachsen et al., 1994). There exists a small amount of exposed rock at two points in the area as well as very little human-made structures. There are also several creeks in the area with varying amounts of seasonal flow. Little agriculture or urban environment exists around the mountain. The New York State Forest Preserve prohibits further land development

\subsubsection{Data Sets}

The area covered by the available data included the study site as well as a significant portion of the southern Catskill Park. All spatial data were downloaded in Google Maps .kmz file format. The land cover map data were provided by a previous study, which used multitemporal Landsat imagery to map vegetation in the Catskill Park (Driese et al., 2004). The surficial mineralogy and bedrock mineralogy maps were provided by the New York State Museum, NYS Education Department, and created by the New York State Geological Survey. The soil map data were provided by the United States Department of Agriculture, Natural Resource Conservation Services. All . $\mathrm{kmz}$ files were downloaded from the website http://www. huttonstreet.org/MapData.html, which had previously compiled the necessary map data for this study site.

The land cover map, created by Driese et al. (2004), contains 10 classifications of the significant vegetation types as well as nonvegetation. This includes primarily broadleaf woodland, however evergreen and deciduous forest also exist in the region. Two of the classifications (human built-up and nonforest) are the only exception to the woodland vegetation. According to the study, there was only a $46 \%$ accuracy using traditional accuracy measurements, however, there was an increased map accuracy of $71 \%$ using fuzzy accuracy assessment measurements. Furthermore, an increase in accuracy to $84 \%$ and $90 \%$ was noted when the class list dropped to four and three classes, respectively.

The surficial geology map has seven classes. The description of each class type is presented in Table 10.1. The bedrock geology map includes only five classes. Each of the five classified units consists of a sequence of rock type (lithology), the primary being the most significant. Table 10.2 illustrates each class. The soil map contained many more classifications than the other data sets, 52 classes in all. All .kmz files came georectified to the World Geodetic System (WGS) 1984 projection. Similarly, each individual .kmz file was matched to overlap the same geographic area, the southern Catskill Park, during the data acquiring. It is important to note, however, that the data only cover the area within the Catskill Park boundary and do not include private property.

Table 10.1 Description of the Surficial Geology

Classifications.

\begin{tabular}{|c|c|}
\hline urficial geology type & Description \\
\hline cent Alluvium & $\begin{array}{l}\text { A mixture of clay, silt, sanc } \\
\text { gravel deposited by flowi }\end{array}$ \\
\hline custrine silt and clay & $\begin{array}{l}\text { Silt and Clay deposits left within lake } \\
\text { regions }\end{array}$ \\
\hline $\begin{array}{l}\text { utwash sand and } \\
\text { gravel }\end{array}$ & $\begin{array}{l}\text { Sand and gravel deposited in glacial } \\
\text { moraines by meltwater }\end{array}$ \\
\hline $\begin{array}{l}\text { eat muck swamp } \\
\text { deposits }\end{array}$ & $\begin{array}{l}\text { Partially decayed organic material } \\
\text { deposited in wetland areas }\end{array}$ \\
\hline d t & Solid rock underlying surface deposits \\
\hline me deposits & $\begin{array}{l}\text { A ridge, hill, or mound of stratified } \\
\text { drift deposited by glacial meltwater }\end{array}$ \\
\hline lacial t & $\begin{array}{l}\text { Unsorted material deposited directly } \\
\text { by glacial ice }\end{array}$ \\
\hline
\end{tabular}

Source: Encyclopedia Britannica (2012).

Table 10.2 Description of the Bedrock Geology Classifications.

\begin{tabular}{lcl}
\hline Geologic Class & Lithology & Geologic Period \\
\hline Oneonta & Shale-sandstone- & Middle-Upper \\
formation & conglomerate & Devonian \\
LowerWalton & Shale-sandstone & UpperDevonian \\
formation & conglomerate & UpperDevonian \\
$\begin{array}{l}\text { UpperWalton } \\
\text { formation }\end{array}$ & $\begin{array}{c}\text { Shale-sandstone - } \\
\text { conglomerate }\end{array}$ & UpperDevonian \\
$\begin{array}{l}\text { Slide Mountain } \\
\text { formation }\end{array}$ & $\begin{array}{c}\text { Sandstone-shale - } \\
\text { conglomerate }\end{array}$ & \\
$\begin{array}{l}\text { Honesdale } \\
\text { formation }\end{array}$ & Sandstone-shale & UpperDevonian \\
\hline
\end{tabular}

Source: US Geological Survey (2012). 
In order to process the spatial data, it was necessary to be able to review, convert, and manipulate the data. Four different software packages were used at different processing stages conducted in this study. Google Earth was used for the initial review of the downloaded (.kmz) files from the source website. FW tools version 2.4.7 was used as a platform for the GDAL/OGR module in order to convert the .kmz files to ArcGIS shapefiles (.shp). ArcGIS Suite 9.3 was the primary software used in this study. Several toolsets were used within the ArcGIS toolbox to process the map data files. For the final processing of the data, two separate programs were used: (1) A statistical tool within a GIS software (ArcGIS) was used to determine a correlation between the four variables (land cover, bedrock geology, surficial geology, and soil types) and (2) a statistical analysis toolset within a spreadsheet software (Microsoft Excel 2011) was used to produce correlation statistics. Both statistical methods were used in order to determine the more efficient process.

\subsection{METHODOLOGY}

Figure 10.2 gives a schematic representation of the general structure of the methodology, which was followed in this study, including data preprocessing, processing, and postprocessing, as they are described in the following subsections.

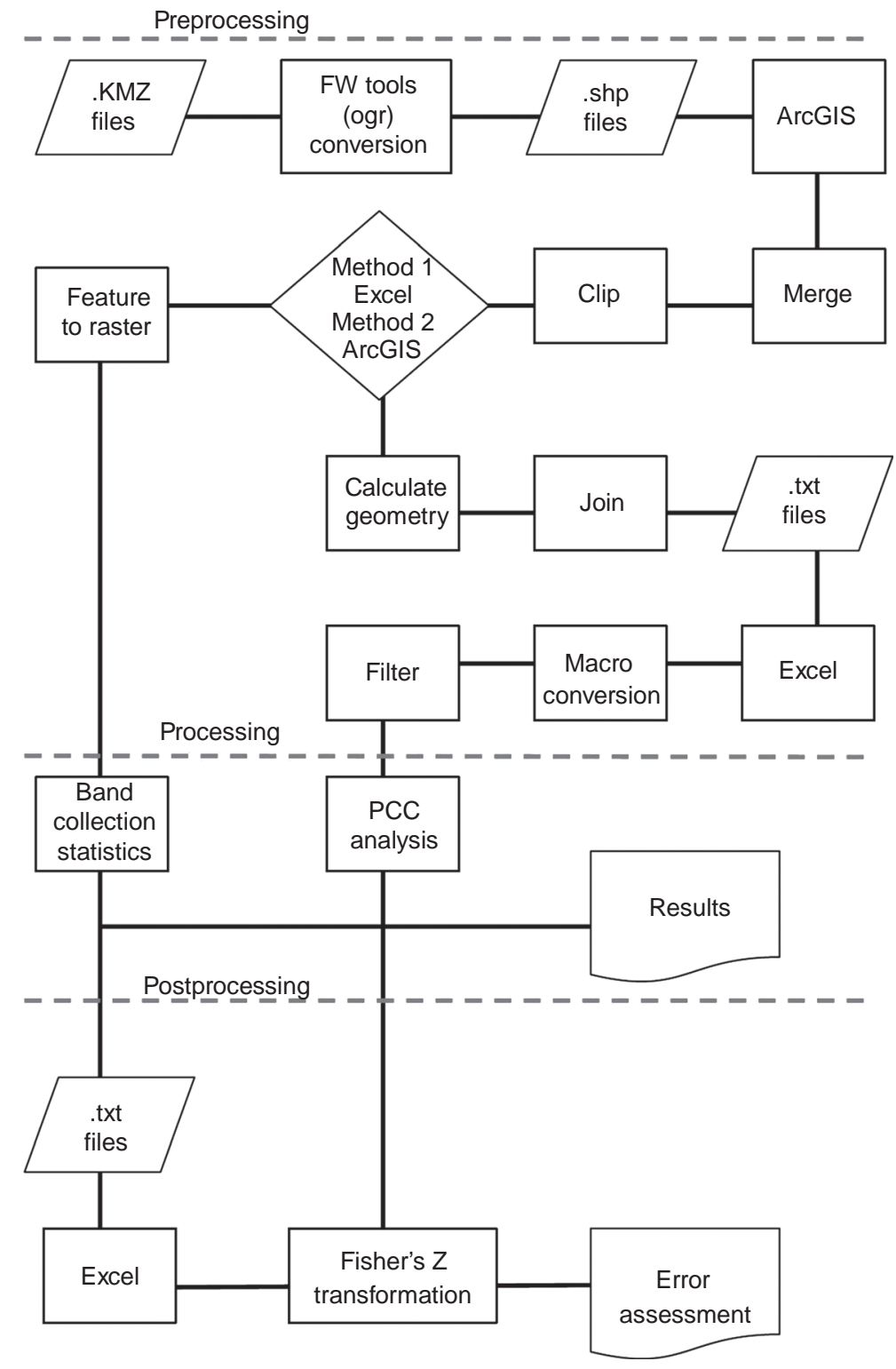

Figure 10.2 Schematic summary of dataprocessing methodology. 


\subsubsection{Data Preprocessing}

The preprocessing of the spatial data involved several steps, with a primary goal to create suitable tables and images for statistical analysis. These steps, presented in the order with which they were performed, were the following:

1. Data Conversion. It was necessary to convert the . $\mathrm{kmz}$ files into a recognizable format for ArcGIS. This was done using the OGR Simple Feature Library command line tool ogr2ogr, within FW Tools command shell.

2. Merge. Following the conversion to shapefiles, several toolsets within ArcMAP were used to preprocess the data. The merge tool was used to create single layer shapefiles for the bedrock, surficial and soil shapefiles. The conversion process had created individual layers for each of the classifications. Each of the shapefiles was then changed to show only the unique values within their attributes, thereby revealing their respective class values.

3. Clip. In order to differentiate the Panther Mountain site from the rest of the data, the clip function was applied to each of the shapefiles.

4. Feature to Raster Conversion. In order to run the statistical analysis within ArcGIS, it was necessary to convert each of clipped vector files into raster images. This was done using the feature to raster conversion tool within arc toolbox. Subsequently, eight new raster images were created, four for each region (land cover, bedrock geology, surficial geology, and soil type). The original vector files continued to be used for the rest of the preprocessing.

5. Calculate Geometry. Coordinate data were added to the land cover layer's attribute table using the calculate geometry tool. Latitude and longitude were calculated for the centroid location of each shape within the layer. The new attribute table was then used to create a point shapefile (import xy data) whereby each point contained land cover type and grid location

6. Join. The land cover point-shapefile's attribute table was joined with each of the three geology classification layers. The result was six new point-shapefiles where each point contained geometric location, land cover type, and one of the three variables (soil type, surficial geology, or bedrock geology).

The data for the six tables went through several processing steps. Several database techniques were used to arrange, convert, and remove data to prepare them for statistical analysis. In order to run the statistical analysis, the description for each land cover and geology type needed to be converted to a numerical value. Representative maps of the entire study area produced during the preprocessing stages are shown in Figure 10.3.

\subsubsection{Data Processing}

Pearson's correlation coefficient $(r)$ was used as the primary statistical interpretation of the correlations between variables. It was assumed that a linear relationship existed between land cover and one of the other variables (bedrock geology, surficial geology, or soil type). However, it was also possible that the other variables might exhibit promising correlations and therefore were also analyzed as such. The $r$ coefficient was calculated using land cover with each of the other variables. There were six combinations between the data variables that were used to determine a correlation: (1) land cover and bedrock geology for Panther Mountain; (2) land cover and surficial geology for Panther Mountain; (3) land cover and soil type for Panther Mountain; (4) land cover and bedrock geology for the surrounding area; (5) land cover and surficial geology for surrounding area; and (6) land cover and soil type for the surrounding area.

\subsubsection{Data Postprocessing}

Statistical significance was calculated at a $95 \%$ confidence interval level for both of the statistical methods used. Pearson's correlation coefficients require a slightly different technique for evaluating amounts of error. Pearson's correlation $(r)$ is not normally distributed; therefore it was necessary to use Fisher's (z) transformation. Once converted to Fisher's ( $\mathrm{z}$ ) it was then possible to determine the upper and lower margins of error. These values were then converted back to $(r)$ values. The following equations were used to calculate the error values:

Conversion to Fisher's z:

$$
z=\frac{1}{2} \ln \left(\frac{1+r}{1-r}\right)=\operatorname{artanh}(r)
$$

where, $z$ is the Fisher's ( $\mathrm{z}$ ) transformation, and $r$ is the correlation coefficient.

Standard error $(S E)$ was calculated for each of the scenarios by:

$$
S E=\frac{1}{\sqrt{N-3}}
$$

where, $\mathrm{N}$ is the paired sample size.

The upper $(\mathrm{Zu})$ and lower $(\mathrm{ZL})$ limits are given by the following equations, where 1.96 is the Z-score for $95 \%$ confidence:

$$
Z_{u}=z+(1.96 \cdot S E)
$$


AN EXPLORATION OF THE PANTHER MOUNTAIN CRATER IMPACT USING SPATIAL DATA AND GIS SPATIAL 131

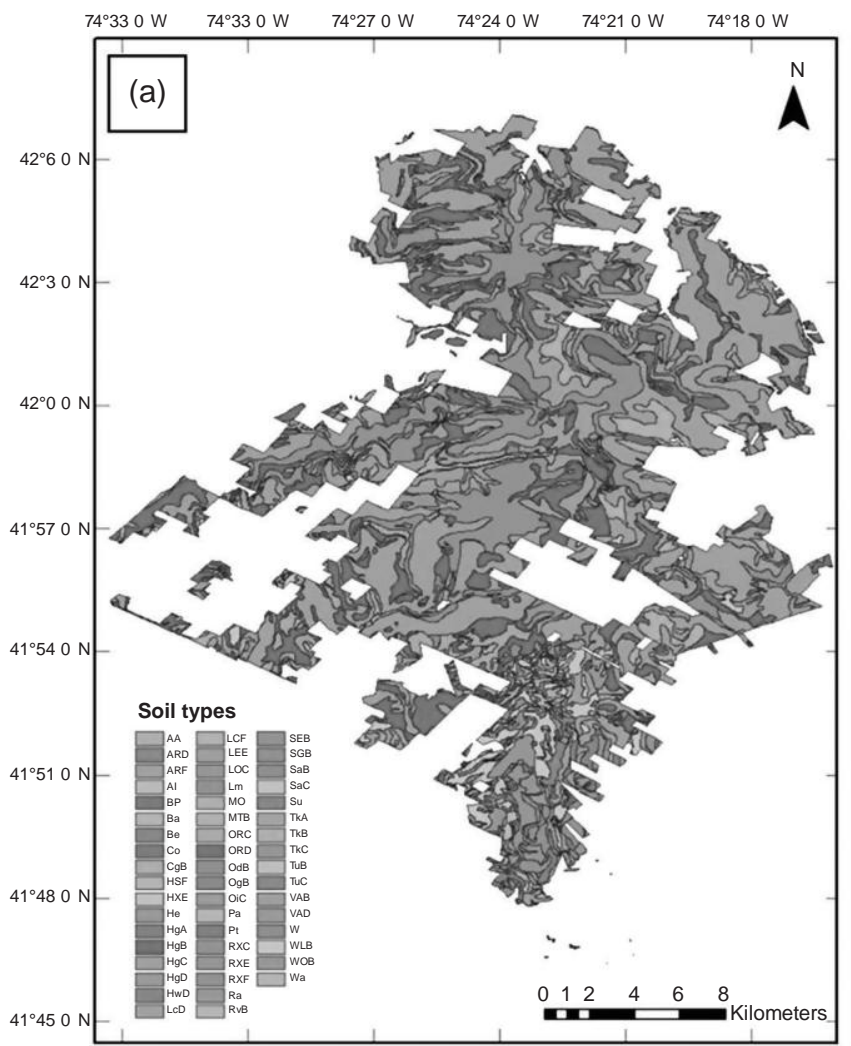

$74^{\circ} 330 \mathrm{~W} \quad 74^{\circ} 30 \mathrm{OW} \quad 74^{\circ} 270 \mathrm{~W} \quad 74^{\circ} 240 \mathrm{~W} \quad 74^{\circ} 210 \mathrm{~W} \quad 74^{\circ} 180 \mathrm{~W}$
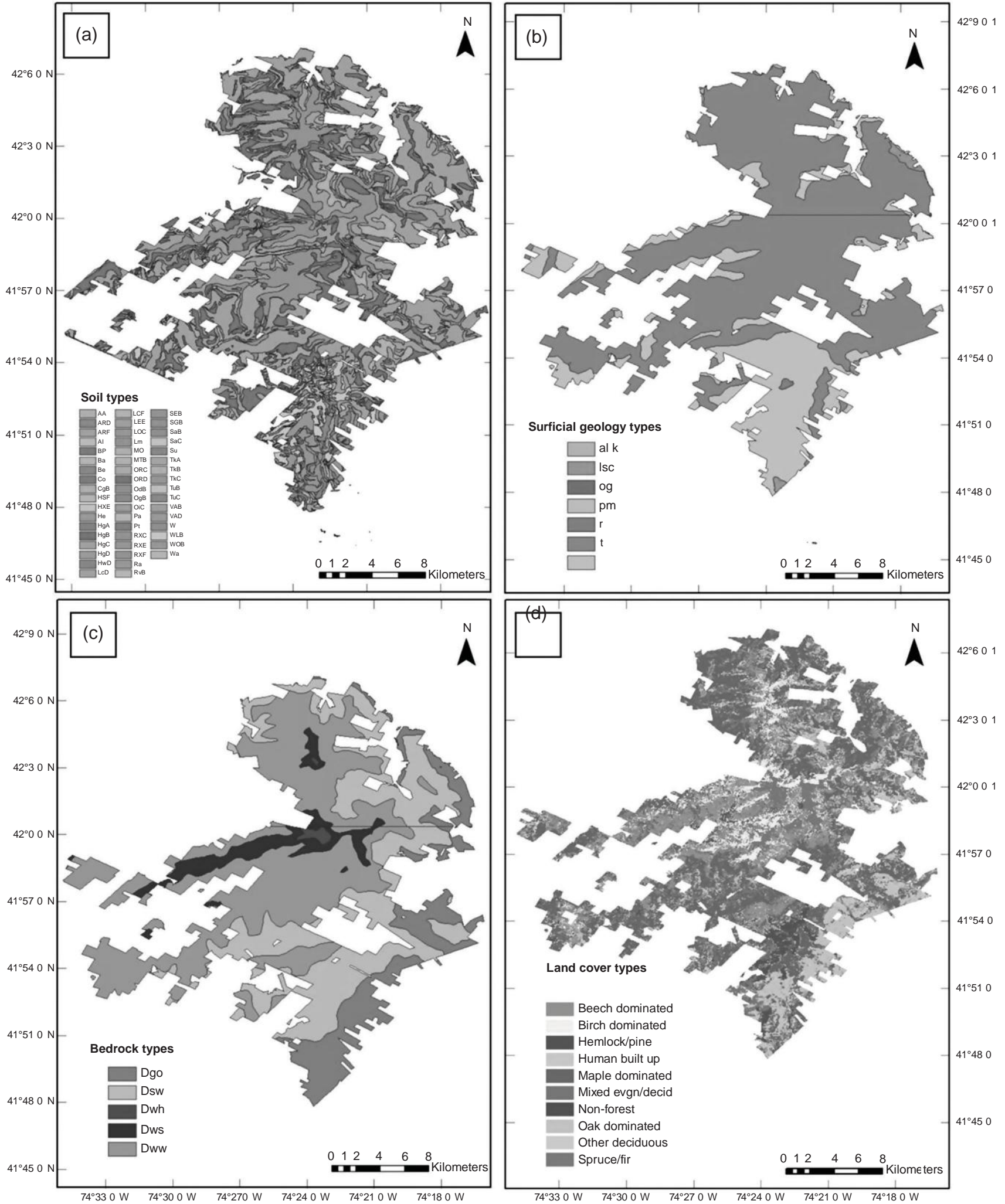

Figure 10.3 Maps of the study area for (a) soil typeclassification (52 classes); (b) surficial geology classification (7 classes); (c) bedrock geology classification (5 classes); (d) land cover classification (10 classes). 


$$
Z_{L}=z-(1.96 \cdot S E)
$$

The intervals were converted back to $(r)$ values by:

$$
r_{u, l}=\frac{\mathrm{e}^{2 \mathrm{z}}-1}{\mathrm{e}^{2 \mathrm{z}}+1}=\tanh \left(r_{u, l}\right)
$$

\subsection{RESULTS}

The results of each of the two methods used to determine a correlation are presented in this section, followed by an error assessment, calculated for a $95 \%$ confidence interval.

\subsubsection{Spreadsheet Software Analysis}

The six scenarios incorporated in the analysis based on spreadsheet program procedures included (1) land cover and soil type at Panther Mountain; (2) land cover and surficial geology at Panther Mountain; (3) land cover and bedrock geology at Panther Mountain; (4) land cover and soil type at the surrounding area; (5) land cover and surficial geology at the surrounding area; (6) land cover and bedrock geology at the surrounding area. The correlations are shown in Table 10.3. A graph of the coefficients clearly shows the correlation differences between Panther Mountain and the surrounding region (Figure 10.4).

The six correlation coefficients produced as a result of the Pearson's correlation analysis highlighted several key points. It is evident that the largest coefficient is Panther Mountain's bedrock geology and land cover scenario $(-0.127)$, while the smallest coefficient belongs to the soil type and land cover scenario of the surrounding area (0.005). The surficial bedrock category held a positive correlation for both regions (Panther 0.049, Surrounding Area 0.074$)$, while both the soil and bedrock scenarios for panther mountain were both negative $(-0.100,-0.127$, respectively). The bedrock scenario for the surrounding area was also negative $(-0.031)$, albeit noticeably less than Panther Mountain's coefficient.

The change in magnitude between each scenario's correlation was calculated to highlight the effects of the

Table 10.3 The Results of the Correlation Analysis in Spreadsheet Software.

\begin{tabular}{lc}
\hline Scenario & Correlation coefficient $(r)$ \\
\hline Surficial geology & 0.074 \\
Soil & 0.005 \\
Bedrock geology & -0.031 \\
Surficial geology Panther & 0.049 \\
Soil Panther & -0.100 \\
edrockgeology Panther & -0.127
\end{tabular}

crater impact at Panther Mountain (Table 10.4). Although the bedrock scenario for Panther Mountain had the largest standalone coefficient, the greatest change in correlation occurred in the soil scenario, which yielded a $10.52 \%$ difference. The bedrock scenario was close behind with $9.61 \%$ but there was little change between the surficial scenarios with only $2.55 \%$.

\subsubsection{GIS Software Analysis}

The correlation analysis conducted within the GIS software produced 12 correlation coefficients; however, only 6 were used to compare with the other correlation method (this was due to the fact that six scenarios conducted with GIS did not pertain to the objectives of the study. They did not use land cover as a variable (but are highlighted to show the potential use of other variables). A graph was also produced illustrating the relationships at Panther Mountain and the surrounding area for land cover and bedrock geology, land cover and surficial geology, and land cover and soil type (Figure 10.5). As depicted in the graph, all correlations were in the positive direction. The highest correlation was found between land cover and surficial geology at the surrounding area, with $\sim 18 \%$. The second largest correlation was between land cover and bedrock geology at Panther Mountain $(\sim 16 \%)$, and the third largest was land cover and soil at the surrounding area $(\sim 11 \%)$ (Table 10.5).

The difference between correlations at Panther Mountain and the surrounding area were also more significant than the spreadsheet software method (Table 10.6). The largest change in correlation was found to be for the land cover and surficial geology scenario, with a total difference of $\sim 13.5 \%(0.1354)$. There was a significant $\sim 10.5 \%(0.1046)$ difference in correlations for the vegetation and bedrock geology scenario. The smallest correlation change was the vegetation and soil scenario with only a $\sim 3 \%(0.0302)$ difference in correlation.

\subsubsection{Error Assessment}

The error produced at the $95 \%$ confidence interval can be seen in Table 10.7, where the correlation values and total error intervals for each scenario are shown, as well as their percentage equivalents.

\subsection{DISCUSSION}

\subsubsection{Spreadsheet Software Analysis Results}

The correlation analysis in the spreadsheet software proved to illustrate a significant difference between the two regions for the land cover and bedrock geology 


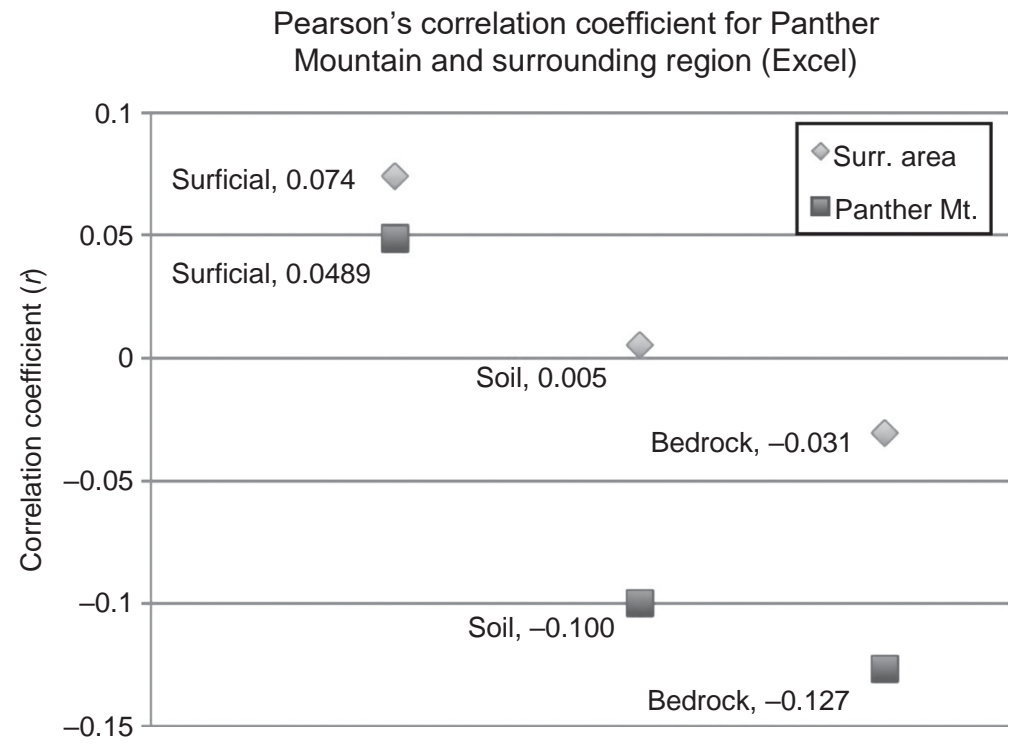

Figure 10.4 Graph of the correlation analysis in spreadsheet software for each of the scenarios. There is a total of six correlation ( $r$ r results, three for Panther Mountain (red) and three for the surrounding area (blue).

Table 10.4 Difference Between Scenario Correlations, in Spreadsheet Software.

\begin{tabular}{lcc}
\hline Scenario & Difference in $(r)$ & Difference $(\%)$ \\
\hline Soil & 0.105 & 10.52 \\
Surficial & 0.026 & 2.55 \\
Bedrock & 0.096 & 9.61 \\
\hline
\end{tabular}

scenario, and the land cover and soil scenario. However, it is necessary to interpret the $(r)$ values themselves to understand the correlation between the variables, at each region. Similarly, it is important to examine possible points of error and limitations set by the data. The correlations between surficial geology and land cover for both scenarios were the only significantly positive results.

Correlation coefficient for Panther Mountain and surrounding region (ArcGIS - Band collection statistics)

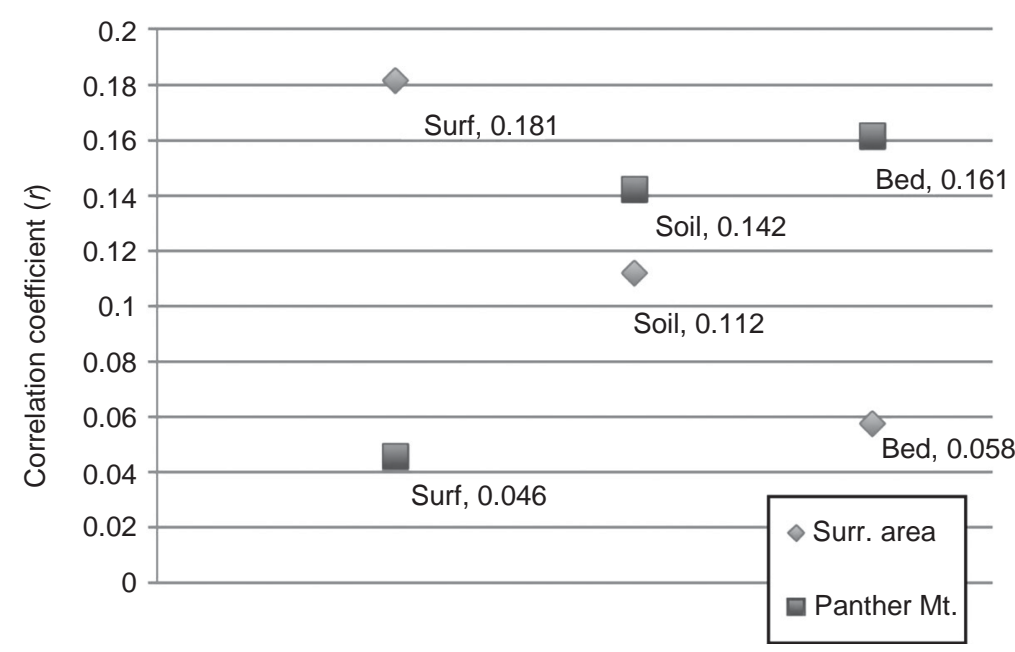

Figure 10.5 Graph of the correlation analysis in GIS for each of the scenarios. There is a total of six correlation (r) results, three for Panther Mountain (red) and three for the surrounding area (blue). 
Although both correlations showed only a $2.6 \%$ difference, they accounted for a $7.4 \%$ and $4.9 \%$ correlation between surficial geology and land cover. This can be interpreted to show that surficial geology may have a link to vegetation type; however there are more variables to consider with this relationship.

The second scenario where soil is compared with land cover for both regions, showed a much unexpected result. The almost nonexistent correlation between soil and land cover at the surrounding region is a puzzling outcome. It is a common understanding that soil type influences vegetation diversity. Looking at the soil map of the surrounding region (Figure 10.3a), it is noticeable that the soil types increase in frequency toward the southern end of the Catskill Park. It is possible that the increase in the surrounding region's sample size added to the discrep-

Table 10.5 The Results of the Correlation Analysis in GIS.

\begin{tabular}{lc}
\hline Scenario & Correlation coefficient $(r)$ \\
\hline Surficial geology & 0.181 \\
Soil & 0.112 \\
Bedrock geology & 0.058 \\
Surficial geology Panther & 0.046 \\
Soil Panther & 0.142 \\
Bedrock geology Panther & 0.161 \\
\hline
\end{tabular}

Table 10.6 Difference Between Scenario Correlations, in GIS.

\begin{tabular}{lcc}
\hline Scenario & Difference in $(r)$ & Difference $(\%)$ \\
\hline Soil & 0.0302 & 3.02 \\
Surficial & 0.1354 & 13.54 \\
edrock & 0.1036 & 10.36
\end{tabular}

ancy between correlations. Furthermore, the Panther Mountain region yielded a negative $(-10 \%)$ correlation between soil and vegetation. This suggests that soil has little to do with vegetation at the surrounding area, yet has a more significant negative association with vegetation at Panther Mountain.

The last scenario showing bedrock and land cover correlation appeared to be the most promising in terms of individual correlations. The correlation between bedrock and land cover at the surrounding area was a low $-3 \%$, suggesting that bedrock has a minor relationship with vegetation. However, the significant $-13 \%$ correlation between bedrock and vegetation at Panther Mountain suggests that bedrock has an increased, negative impact on vegetation. This supports the argument that the Panther Mountain crater impact has influenced the bedrock geology in such a way as to distinguish it from the surrounding area. The bedrock in turn has impacted the distribution of vegetation differently than the other region.

The coefficient values themselves show little correlation in their own right. All the values fall under a $13 \%$ correlation. This has little to show in terms of significant linear dependency. However, the aim of this study was not to determine linear dependency necessarily, but to show the difference in correlation between the two regions. The $11 \%$ difference between the soil scenario correlations is a more profound result (Table 10.4). Similarly, the almost $10 \%$ difference between the bedrock scenario correlations is also more significant than the correlation values themselves (Table 10.4). This amount of change between the two regions is cause to question the unforeseen differences between the Panther Mountain crater and the surrounding area, especially considering that

Table 10.7 The Results of the Error Assessment for All Scenarios (18 Total).

\begin{tabular}{|c|c|c|c|c|}
\hline Scenario & $P C C(r)$ & Total error (+/-) (95\% conf.) & $\%(r)$ & $\%$ error $(+/-)$ \\
\hline $\begin{array}{l}\text { Surficial surrounding (spreadsheet) } \\
\text { Soil surrounding (spreadsheet) } \\
\text { Bedrock surrounding (spreadsheet) } \\
\text { Surficial Panther (spreadsheet) } \\
\text { Soil Panther (spreadsheet) } \\
\text { Bedrock Panther (spreadsheet) } \\
\text { Surficial surrounding (GIS) } \\
\text { Soil surrounding (GIS) } \\
\text { Bedrock surrounding (GIS) } \\
\text { Bedrock soil surrounding (GIS) } \\
\text { Bedrock surficial surrounding (GIS) } \\
\text { Surficial soil surrounding (GIS) } \\
\text { Surficial Panther (GIS) } \\
\text { Soil Panther (GIS) } \\
\text { Bedrock Panther (GIS) } \\
\text { Bedrock soil Panther (GIS) } \\
\text { Bedrock surficial Panther (GIS) } \\
\text { Surficial soil Panther (GIS) }\end{array}$ & $\begin{array}{r}0.074 \\
0.005 \\
-0.031 \\
0.049 \\
-0.100 \\
-0.127 \\
0.181 \\
0.112 \\
0.058 \\
-0.008 \\
-0.300 \\
0.023 \\
0.046 \\
0.142 \\
0.161 \\
0.103 \\
0.059 \\
-0.028\end{array}$ & $\begin{array}{l}0.010 \\
0.010 \\
0.010 \\
0.019 \\
0.019 \\
0.019 \\
0.014 \\
0.015 \\
0.013 \\
0.009 \\
0.009 \\
0.009 \\
0.009 \\
0.009 \\
0.009 \\
0.015 \\
0.015 \\
0.015\end{array}$ & $\begin{array}{r}7.41 \\
0.52 \\
-3.09 \\
4.86 \\
-10.00 \\
-12.69 \\
18.12 \\
11.17 \\
5.76 \\
-0.78 \\
-20.01 \\
2.31 \\
4.58 \\
14.19 \\
16.11 \\
10.29 \\
5.91 \\
-2.84\end{array}$ & $\begin{array}{l}0.99 \\
1.04 \\
0.99 \\
1.93 \\
1.92 \\
1.90 \\
1.42 \\
1.45 \\
1.32 \\
0.90 \\
0.86 \\
0.90 \\
0.90 \\
0.88 \\
0.87 \\
1.45 \\
1.46 \\
1.47\end{array}$ \\
\hline
\end{tabular}


both regions have formed under the same geologic processes. The implication of this difference in regional correlation may later contribute to a more efficient detection method for impact craters.

\subsubsection{GIS Software Analysis Results}

The results of the correlation analysis within the GIS software were significantly different than those produced from the analysis conducted in the spreadsheet software. This is most likely attributed to a difference in technique. Nonetheless, it was evident that a distinct difference was found between Panther Mountain and the surrounding area correlations. A significant difference between the two approaches was that in the case of the GIS analysis, there were no negative correlations. This claims that there was a positive relationship between all the variables for each scenario. Unlike the spreadsheet software method, the largest correlation was found between land cover and surficial geology at the surrounding area ( 18\%), suggesting that surface geology has a more significant impact on vegetation away from the crater site. Looking at the surficial geology map (Figure 10.3b), it is evident that surface geology is more diverse at the surrounding region. The high land cover and bedrock correlation at Panther Mountain $(\sim 16 \%)$ also supports the idea that the underlying bedrock has had an impact on vegetation at the surface of the crater site.

One of the most visible differences between methods is the high correlation for the land cover and soil scenario at both regions (for the GIS analysis). Although the difference in correlations between each region is minimal, it suggests that soil has a positive relationship with vegetation for both sites. This is an expected result, however (soil properties are known to correlate with vegetation), which validates the GIS method over the spreadsheet software method (which showed a negative correlation).

A low correlation between land cover and surficial geology, but a high correlation between land cover and bedrock geology at Panther Mountain also provide further evidence toward the argument of the crater's presence in the area. In reference to the surficial geology map (Figure 10.3b), it is evident that a majority of the surficial geology at Panther Mountain is actually bedrock. This is supportive of the idea that the thousands of years of erosion at Panther Mountain that exposed the crater outline also removed much of the surficial geology.

Perhaps the most substantial piece of evidence for the Panther Mountain crater site is found in the differences between the scenario correlations (Table 10.6). The results showed an almost $14 \%$ difference in correlation for the land cover and surficial geology scenario. Similarly, there was a $10 \%$ change in correlation for the land cover and bedrock geology scenario. These percentages present a validation for the location of a crater impact at Panther Mountain, provided the meteor disturbed the underlying bedrock on impact (in conjunction with complex crater creation).

The correlations between bedrock and surface geology, bedrock geology and soil type, as well as surficial geology and soil type were also calculated. Although these values were not part of the objectives of the study, they still illustrate several key points. As seen in Table 10.8, there are two significant correlations to be noted. Apart from the correlations that are below 3\% ( $\mathrm{r}<\sim 2.8)$, the bedrock geology and soil correlation for Panther Mountain as well as the surficial geology and bedrock geology correlation for the surrounding area are greater than $10 \%$. At the Panther Mountain impact site, bedrock geology is found to have a $\sim 10 \%$ positive correlation with soil type. This is an encouraging result, as bedrock is the primary geologic layer beneath soil at Panther Mountain (as oppose to other surficial geology types). A higher percentage would have been expected, but a linear dependency is not necessarily the case between these two variables. The reverse is happening at the surrounding area, however. A $-20 \%$ correlation exists between surficial geology and bedrock geology at this region. With the strongest correlation (albeit negative) between any of the variables, this result suggests bedrock geology has a significant negative relationship with surficial geology (or vice versa) outside the crater site. This supports the Panther Mountain impact site because it suggests that surficial geology has a greater distribution in the surrounding area, whereas inside the crater site, bedrock is the primary geology type at the surface.

\subsubsection{Combined Evaluation}

Although the graphs of the correlations produced using the two methods appear to be significantly different, there is a similarity between them. The magnitudes of each scenario for both graphs are comparable. In the spreadsheet software analysis, the Panther Mountain correlations from largest to smallest are bedrock geologysoil-surficial geology. In the GIS analysis, the Panther Mountain correlations from largest to smallest are in the same order, bedrock geology-soil-surficial geology. In the surrounding area scenario, this case is almost true;

Table 10.8 GIS Analysis Correlation Results for the Six Scenarios That Did Not Include Land Cover As a Variable.

\begin{tabular}{lcc}
\hline Scenario & Bedrock Geology & Soil \\
\hline Surficial Geology Panther & 0.059 & -0.028 \\
Bedrock Geology Panther & - & 0.103 \\
Surficial Geology surrounding & -0.200 & 0.023 \\
Bedrock Geology surrounding & - & -0.008 \\
\hline
\end{tabular}


however the vegetation and soil correlation in this scenario is nearly nonexistent.

There are several areas within this study that may have impacted the results of each method and are worth examining. The selection of the surrounding region using the clip tool may have influenced the low correlation between soil and vegetation. Although both the Panther Mountain region and the surrounding area are both part of the southern Catskill Park, there may be areas within the park that have considerably different geology and soil types. Similarly, the entire extent of the Catskill Park was not used for this study, only the southern region. Would the data have provided for the whole park, there is a possibility that the change in the correlation may have been different.

The technique used for the spreadsheet software method of this study examined the relationship between point data. Although the original data were spatially distinctive, the spatial components were ignored for the final processing. Since the data were split between two regions, Panther Mountain and the surrounding area, it was not necessary to maintain locational accuracy but rather keep paired data points together. It is possible, however, to examine the spatial relationships between the data sets as a whole (as in the GIS software).

GIS statistical analysis was used to examine correlations between variables based on spatial locations of an entire area. With this method, correlations were determined using several layers, each containing one of the four variables: (1) vegetation, (2)surficial geology, (3)bedrock geology, and (4)soil type. The results of this technique were visibly different, although a similar pattern was recognized. The differences between the correlations themselves can be seen in Table 10.9.

There was not a significant difference between the correlations in a majority of the cases; however two of the cases showed substantial differences. Land cover and surficial geology and land cover and soil type at the surrounding area both showed over a $10 \%$ difference in correlations between the two methods. It is possible that this $10 \%$ discrepancy can be attributed to error in the processing of data. It is also possible that spatial characteristics (not used with the spreadsheet software method) have a greater impact on correlation than previously thought. Further study should address this result.

Table 10.9 The Difference Between the Results From Each Method, Shown for Both Panther Mountain and the Surrounding Area.

\begin{tabular}{lcc}
\hline Scenario & Surrounding area diff. & Panther Mt. diff. \\
\hline Surficial & 0.107 & 0.003 \\
Soil & 0.107 & 0.042 \\
Bedrock & 0.027 & 0.034
\end{tabular}

The low correction coefficients for vegetation overall ( $r<20 \%$ for all land cover correlations), suggest that there are other factors affecting the distribution of vegetation. Although other variables were considered, it was the difference between correlations that was most important, not necessarily the extent of the correlation coefficients. Variables, such as topography, slope, aspect, and vicinity to water, all have effects on vegetation growth. Further studies may use these variables in conjunction with bedrock to show a greater correlation.

The results show that error values are overall low, less than $2 \%$ error for all cases. However, the smaller correlations suffered the greatest error. In some cases, the error is greater than the correlation. This is perhaps due to the idea that as a correlation approaches zero (no correlation), error values are increasingly unreliable (considering that a positive correlation cannot become a negative correlation through error alone). It should also be noted that the GIS method scenarios have lower error percentages overall as compared with the spreadsheet software method. The strongest correlations, within the GIS scenario, also have some of the lowest error percentages. This significantly supports the results of the GIS method (and spatial correlation) over the spreadsheet software method.

\subsection{CONCLUSIONS}

There were three primary objectives of this study, namely: (1) create a land cover map using classified GIS data for Panther Mountain and surrounding area; (2) create mineralogy and soil type maps using classified GIS data for Panther Mountain and surrounding area; and (3) compare correlations between variables at Panther Mountain and the surrounding area. These objectives were fulfilled in order to provide evidence for the main goal of this work, which was to support the statement: "The differentiation of correlations between vegetation and geology at and around Panther Mountain, New York provides evidence for the location of a terrestrial meteor impact crater." Additionally, although it was not the primary initiative of this study, it can be stated that the accuracy of the GIS method over the spreadsheet software method supports the idea that spatial location can have a significant role in correlation analysis.

The difference in correlations between the coefficients of the two regions provides some evidence for the crater impact at Panther Mountain. Although these correlation values by themselves do not provide enough evidence of the existence of a crater impact, they do provide supporting evidence of an impact site. Coupled with other statistical analyses, perhaps the effectiveness of this statistical analysis may hold greater evidence for studying impact craters. 
This study has addressed a new method for examining impact sites using correlation statistics. At this point, it is not possible to compare these results with other research methods for there has been no prior examination of terrestrial impact sites using a correlation comparison. Alternatively, this method can be applied to support current studies of terrestrial crater sites. Similarly, there is much that can be added to this method in order to improve accuracy and efficiency.

What do the results of this study suggest about the implication of using GIS and statistics to provide evidence for terrestrial impact craters? GIS combined with statistical analysis is an efficient tool that can be used to show relationships between data types. This study examined how Pearson's correlation coefficient, used in conjunction with GIS data, was able to illustrate distinctions in the correlation between land cover and soil type, land cover and surficial geology, and land cover and bedrock geology at the Panther Mountain crater and the surrounding region. It is by initiating alternative methods of analysis that the state of scientific research can be advanced to benefit all levels of the scientific community.

\section{ACKNOWLEDGMENTS}

The authors are grateful to the reviewers for their constructive feedback, which improved the manuscript. GPP's contribution, in particular, has been supported by the FP7- People project ENViSIon-EO (project reference number 334533) and the author gratefully acknowledges the financial support provided.

\section{REFERENCES}

Aich, S., \& Gross, M. R. (2008). Geospatial analysis of the association between bedrock fractures and vegetation in an arid environment. International Journal of Remote Sensing, 29 (23), 6937-6955.

Chen, B.-M., Wang, G.-X., Cheng, D.-L., Deng, J.-M., Peng, S.-L., $\&$ An, F.-B. (2007). Vegetation change and soil nutrient distribution along an oasis-desert transitional zone in northwestern China. Journal of Integrative Plant Biology, 49 (11), 1537-1547.

Donofrio, R. R. (2010). New York's Panther Mountain impact crater: Enormous gas potential without hydraulic. Oklahoma City, $1-11$.

Driese, K. L., Reiners, W. A., Lovett, G. M., \& Simkin, S. M. (2004). A vegetation map for the Catskill Park, NY, derived from multi-temporal Landsat imagery and GIS data. Northeastern Naturalist, 11(4), 421-442.

Gerdol, R., Ferrari, C., \& Piccoli, F. (1985). Correlation between soil characters and forest types: A study in multiple discriminant analysis. Vegetation, 60(1), 49-56.
Guterl, F. (2000). The Panther Mountain Crater. DISCOVER Magazine. Retrieved from discovermagazine.com/2000/aug/ featcrater.

He, X.-Y., Wang, K.-L., Zhang, W., Chen, Z.-H., Zhu, Y.-G., \& Chen, H.-S. (2008). Positive correlation between soil bacterial metabolic and plant species diversity and bacterial and fungal diversity in a vegetation succession on Karst. Plant and Soil, 307(1-2), 123-134.

Isachsen, Y. (1998). Metallic Spherules and a Microtektite Support the Interpretation of a Buried Impact Crater Beneath Panther Mountain in the Central Catskill Mountains, New York. Meteoritics \& Planetary Science, 33.

Isachsen, Y., Wright, S. F., \& Revetta, F. A. (1994). The Panther Mountain circular feature possibly hides a buried impact crater. Northeastern Geology, 16(2), 123.

Neff, A. J. C., Reynolds, R., Sanford, R. L., Fernandez, D., Lamothe, P., \& Neff, J. C. (2006). Controls of bedrock geochemistry on soil and plant nutrients in southeastern Utah. Ecosystems, 9(6), 879-893.

Pastor, J., Aber, J. D., Mcclaugherty, C. A., \& Melillo, J. M. (1982). Geology, soils and vegetation of Blackhawk Island, Wisconsin. American Midland Naturalist, 108(2), 266-277.

Puy, D. D. U., \& Moat, J. (1996). A refined classification of the primary vegetation of Madagascar based on the underlying geology: Using GIS to map its distribution and assess it. Biogeographic de Madagascar, 205-218.

Rajmon, D. (2007). Suspected Earth Impact Sites database. Houston, TX. Retrieved from http://impacts.rajmon.cz/ IDdata.html.

Rodríguez-Loinaz, G., Onaindia, M., Amezaga, I., Mijangos, I., \& Garbisu, C. (2008). Relationship between vegetation diversity and soil functional diversity in native mixed-oak forests. Soil Biology and Biochemistry, 40(1), 49-60.

Searcy, K. B., Wilson, B. F., \& Fownes, J. H. (2003). Influence of bedrock and aspect on soils and plant distribution in the Holyoke Range, Massachusetts. Journal of the Torrey Botanical Society, 158-169.

Stothoff, S., Or, D., Groeneveld, D., \& Jones, S. (1999). The effect of vegetation on infiltration in shallow soils underlain by fissured bedrock. Journal of Hydrology, 218(3-4), 169-190.

Williard, K. W. J., Dewalle, D. R., \& Edwards, P. J. (2005). Influence of bedrock geology and tree species composition on stream nitrate concentrations in mid-Appalachian forested watersheds. Water, Air, and Soil Pollution, 160, 55-76; doi.org/10.1007/s11270-005-3649-4

Xu, X.-L., Ma, K.-M., Fu, B.-J., Song, C.-J., \& Liu, W. (2008). Relationships between vegetation and soil and topography in a dry warm river valley, SW China. Catena, 75(2), 138-145.

Yang, X., Zhang, K., Hou, R., \& Ci, L. (2007). Exclusion effects on vegetation characteristics and their correlation to soil factors in the semi-arid rangeland of $\mathrm{Mu}$ Us Sandland, China. Frontiers of Biology in China, 2(2), 210-217.

Zumsprekel, H., \& Bischoff, L. (2005). Remote sensing and GIS analyses of the Strangways impact structure, Northern Territory. Australian Journal of Earth Sciences, 52(4-5), $621-630$ 
